\title{
An Empirical Analysis of Behavioral Flexibility, Relationship Integration and Strategic Flexibility in Supply Chain Agility: Insights from SMEs Sector of Pakistan
}

\author{
Mirza A. Haq * $\quad$ Irfan Hameed ${ }^{\dagger} \quad$ Abdul Raheem $\ddagger$
}

\begin{abstract}
Supply chain agility (SCA) has become an important concept these days and gained a great deal of attention from the research fraternity. Researchers and scholars have mainly examined the dimensions of integration and flexibility as the antecedents of SCA from conceptual lenses in the past and suggested further explanations from empirical testing. Thus, this research aimed to investigate three key drivers of supply chain agility - i.e., strategic flexibility, employees' behavioral flexibility and relational (external) integration. The sample is comprised of 147 SMEs operating in Pakistan, collected via survey and then tested using moderated mediation structural equation modelling in MPlus software. As per the findings, customer integration, employees' behavioral flexibility and strategic flexibility have direct influence on supply chain agility (SCA). In addition to that, customer integration has indirect impact on SCA via strategic flexibility. Complexity, as a moderator, has conditional positive influence on the relationship between customer integration and $S C A$. This research advances supply chain literature by adding relationship-centric view in developing flexible and agile supply chains. Overall, the findings suggest Pakistani SME practitioners to allocate resources to activities that build flexible supply chains and invest in activities that create strong ties among downstream supply chain partners.
\end{abstract}

Keywords: Supply chain agility, integration, flexibility, moderated mediation SEM, Small \& medium enterprises.

\section{Introduction}

The change in business environment and proliferating dynamicity had lead the organizational focus to shift from economies of scale to economies of scope. The practitioners and scholars have raised their concerns for this volatility of business environment since decades. The recent trend caused the firms to shift from stable environment, volume and low cost production to information based, customized and shorten product life cycles (Christophe \& Gaudenzi, 2015). Supply chain of a firm is one of the highly affected segments with changing demand, technology and taste. Dynamicity in business environment is not a new term and is also acknowledged by researchers and practitioners in large scale enterprises;

\footnotetext{
*Faculty of Business Administration, IQRA University, Karachi. E-mail: amin.ulhaq@iqra.edu.pk

${ }^{\dagger}$ IQRA University, Karachi. E-mail: ifran.h@iqra.edu.pk

‡IQRA University, Karachi.
} 
however, empirical works in the context of small and medium enterprises (SMEs) are very limited.

SMEs are privately owned with all finances provided by the owner him/herself. SMEs are small-medium in size with employees ranging from 1 to 500 (Savrul, Incekara, \& Sener, 2014); and though SMEs are known to have higher level of flexibility, they possess very few resources as compared to big enterprises (Malekifar, Taghizadeh, Rahman, \& Khan, 2014). Small and medium enterprises (SMEs) are extremely important for the progress and growth of developing country like Pakistan. According to Khan, Liang, and Shahzad (2014), SME sector has contributed 40\% in the GDP growth of Pakistan. In addition to that, this research further stated that $25 \%$ exports of the country are due to SME sector. This sector is providing employment to $82 \%$ employees of overall Pakistani job market (Kantola, Nazir, \& Barath, 2018). In 1998, the government of Pakistan (GoP) started small and medium enterprise development association (SMEDA) to support SMEs sector in Pakistan. Nowadays SME sector is widely active in all major cities of Pakistan. In line with Kantola et al. (2018), 3.2 million SMEs in number are currently operating under SMEDA in Pakistan.

The question arises whether flexibility alone is enough to adapt to changes (Braunscheidel \& Suresh, 2009). Globalization, unexpected market dynamics, increasing focus on variety and frequent technological changes are further supplementing the significance of Supply Chain Agility (SCA). The convention that SCA is only suitable for big firms focusing on innovative products is now being considered equally fit in the context of SMEs. Striving for survival and growth have forced small firms to work in collaboration with their partners and shift their focus from volume to variety (Malekifar et al., 2014); hence, the importance of adapting in time is more crucial nowadays than before. It is evident that the need to be agile vary from industry to industry (D. Teece, Peteraf, \& Leih, 2016); however, means to be agile also differ from industry to industry is the phenomenon which needs further research.

It has been acknowledged by a number of authors in operations management domain that SCA may help firms to speed up the adaptation process and eventually achieve competitive edge, if their supply chain is flexible and there is a close bonding among supply chain partners (Maylor, Meredith, Söderlund, \& Browning, 2018; Hameed, Waris, \& ul Haq, 2019). Despite of the fact, relational and flexible dimensions of agile supply chains have not been largely inspected in past studies. The focus of this research, therefore, is to understand the role of flexibility and relational integration to make supply chains more agile. In particular, this area of investigation seems to be overlooked in empirical research (Gligor, Holcomb, \& Stank, 2013). A few attempts have been made to inquire these factors separately or in a combination of one or two; however, an integrative perspective of relational integration, strategic flexibility in creating agile supply chains is missing in literature. This is important to examine as relational integration often lead to integration of process among supply chain partners we can have a deeper understanding about the implications of development of agility across supply chains.

The above problem is relevant to Pakistani context as a number of large international firms are outsourcing their work to firms operating under the SME sector of Pakistan. Large firms abroad outsource their work to local firms in Pakistan (Kantola et al., 2018). 
Numerous international firms also collaborate with these local firms on certain projects (Boehm, 2002). Utilization of agile methods and strategies enable these enterprises to collaborate frequently with the international clients that brings value addition in the supply chain and consequently become a competitive advantage. This research is also significant because adoption of the proposed framework of agile supply chain will help SMEs to become more productive, reduce communication gaps with these international firms and improve the quality of the product.

In line with the above argument, there has been numerous research work available on the concept of agility in large enterprises; however, the studies on same in SME sector are very limited (Ståhle, Ahola, \& Martinsuo, 2019). Scarcity of this literature is quite astonishing as SMEs are the backbone for the progress and growth of any country. It is also surprising to learn that the research work on supply chain agility in SME sector of Pakistan have been overlooked; whereby $82 \%$ employment of Pakistani job market is contingent upon this sector. Therefore, this research aims to fulfill the above mentioned gaps by answering how relational integration (i.e., customer and supplier side) and employees' behavioral flexibility influence SCA in SME sector of Pakistan.

\section{Literature Review}

\section{Theoretical Background}

Resource based view considers agility as a core competency that is achieved by numerous forms of flexibilities (Koh, Gunasekaran, Morris, Obayi, \& Ebrahimi, 2017). According to resource based view, agility is achieved by synergising different form of flexibility in firms, which then results into competitive advantage.

Knowledge based view is an extension of RBV, which suggests that knowledge is the most valuable asset of a firm to achieve competitive advantage and it can be shared without losing it, unlike other resources (Koh et al., 2017). Rumsfeld explained that there are four quadrants of knowledge management - i.e., known-knowns, known-unknowns, unknownknowns and unknown-unknowns. In this perspective, employees can be pushed into learning cycle to support the adaptation process of organizations (Senge, 1990; Argyris, 1982). Knowledge management enhances the capability to be agile and enable firms to adapt and respond to the changes in the environment (Goldman, Nagel, \& Preiss, 1995).

According to Relational view (J. H. Dyer \& Singh, 1998) importance of knowledge is not debatable; however, sharing of knowledge without formal connection is not feasible. Therefore, it is pertinent for the organizations to have healthy and lasting relationship with their customers and suppliers. On the other hand, transactional cost theory argues that integration with partners is costly, and increases dependency on its supply chain partners (Marcone, 2014). Eventually, this dependency decreases the organizational flexibility and agility. Contingency theory suggests that every organization is unique and its response to the dynamic environment may also vary.

In line with the principles of dynamic capability theory, a firm must have distinct capabilities to survive in a dynamic environment (D. J. Teece, Pisano, \& Shuen, 1997). According to Wernerfelt (1984), competitive advantage can be achieved either by capital- 
izing upon existing capabilities or by developing new ones. Dynamic capabilities (DC) are closely tied with the amalgamation of three elements - processes, positions, and path. These three factors help in developing SCA to adapt and capitalize on the change in the external environment.

In addition to the above, empirical studies have also emphasized the use of dynamic capabilities in enhancing supply chain performance. For instance, Allred, Fawcett, Wallin, and Magnan (2011) carried out a mixed method research research and suggested that supply chain orientation is indirectly related to organizational performance through internal and external integration among supply chain partners. Besides, Chiang, KocabasogluHillmer, and Suresh (2012) conducted a survey and found out that strategic sourcing and flexibility are important factors in creating agile supply chains. On the other hand, Aslam and Azhar (2018) has called for a need to examine the integrative view of operational capabilities in supply chains. In addition, Irfan, Wang, and Akhtar (2019) posits that competency-capability framework is inconsistent and it can vary due to product complexity. Based on these above theoretical and empirical foundations, this study proposes the following framework.

Figure 1

Theoretical model

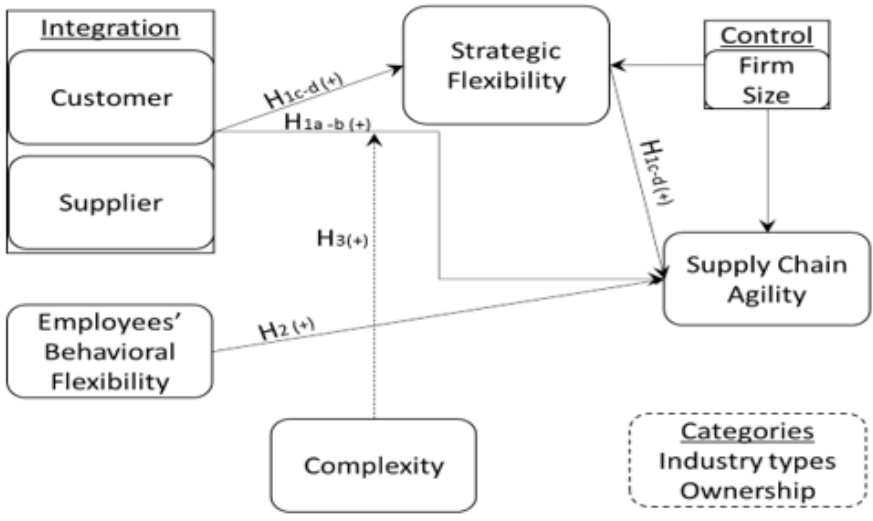

\section{Supply Chain Agility}

The concept of Agility was first introduced by Iacocca University. Though there are numerous definitions and interpretations of SCA but the essence of all is the same. Agility in business context means how quickly firms respond to the changing environment (Nagel \& Dove, 1991). Swafford, Ghosh, and Murthy (2008) said that level of SCA is a barometer to measure firm's strength. Braunscheidel and Suresh (2009) defined SCA as an internal and external capability of a firm, in unification with its main suppliers and customers, to respond to changes in market and environment in a timely manner. Manufacturing systems of innovative products shall not only be flexible, but also agile (Rasouli, 2019). Furthermore, proliferating variety is making SCA a compulsory component to diminish the trade-off between product variety and supply chain performance. 
Additionally, adoption of lean/agile practices have been observed amongst market leaders (Aitken, Christopher, \& Towill, 2002). Simply stating, lean strategy is ideal when organizations employ low customization approach or cost leadership strategy. On the other hand, agility is much needed for organizations following differentiation strategy. Researchers Palmier (2014) argued that organizations at large employ a hybrid strategy by attempting to minimize cost and still able to provide variety to their customers. Hence, improved customer satisfaction and efficiency can be attained by adopting agile practices.

\section{Relationship Integration and Supply Chain Agility}

The role of relationships is equally important in the decision making process of firm (Mitrega, Forkmann, Zaefarian, \& Henneberg, 2017). The integrating inter-organization increase the strategic flexibility. This relationship relies on knowledge transfer, communication, investment and collaboration which then leads to increase in strategic flexibilities (Parente, Baack, \& Hahn, 2011). SCA depends on processes, which includes integration, modification and transformation of abilities and various types of flexibilities. SCA involves internal capabilities as well as involving key suppliers and customers. The main source of sustainable competitive edge in dynamic market of products is not specific, as the value of resources as strategic resources erode with time (Dierickx \& Cool, 1989; Koh et al., 2017).

In the reviewed literature, the research works on supply chain agility have majorly focused upon process integration to design efficient and effective supply chain (Mitrega et al., 2017). However, studies on relationship integration affecting supply chain agility are very limited. According to Childerhouse, Aitken, and Towill (2002), it is important to fill this gap and examine the process and relationship integration together in order to have flawless supply chain operations. Past research suggested that relationship integration play an important role in supply chain activities (Ritchie \& Brindley, 2004). This argument was further extended by Harland (1996); Christopher and Gattorna (2005) who emphasized the significance of relationship integration in supply chain management. Stank, Keller, and Daugherty (2001) referred relationship integration as "a shared mental framework with customers and suppliers regarding inter-enterprise dependency and principles of collaboration". This definition stresses the importance of inter-organisational relationships in terms of trust, commitment, information sharing, communication, risk/reward sharing and relationship-specific investment (Clements, Dean, \& Cohen, 2007; Simatupang \& Sridharan, 2005). Relationship integration between supply chain partners is one of the key predictors for smooth supply chain operations (Mitrega et al., 2017). Therefore, it is argued that there is a need to extend relationship integration as predictor in the context of supply chain agility. Thus it is proposed that:

$H_{1 a}$ : Relationship integration (Customer) have significantly positive impact on SCA.

$H_{1 b}$ : Relationship integration (Supplier) have significantly positive impact on SCA. 


\section{Mediating Role of Strategic Flexibility}

In literature, strategic flexibility is referred to a capability of a firm to adjust its strategic decisions to respond to the changes in the external environment (Aaker \& Mascarenhas, 1984; Price, Beach, Muhlemann, Sharp, \& Paterson, 1998). Strategic flexibility has three components - supply management, product-related flexibility, and process flexibility. Supply management is the ability of the firm to meet changing demands of the customers while managing flow of supplies from suppliers. Whereas, product-related flexibility is referred to introduce new products or update previous products to suit current market without huge impact on cost and supply chain.

Additionally, process flexibility is about adjusting organizational processes to keep-up with changes in environment. Strategic flexibility include the decisions about acquiring new resources through wide range of strategic alternatives (Bowman \& Hurry, 1993) or being able to utilize old resources for different productions. In a nutshell, firms with high strategic flexibility have adaptable resource pools; which provide them strategic alternatives to effectively manage 'surprise'. Strategic flexibility also helps firms to promptly react to new technologies and opportunities in the market. SCA can be achieved by synergizing with all partners in the supply chain (Agarwal, Shankar, \& Mandal, 2006).

Past studies have examined the direct role of strategic flexibility in the context of supply chain agility and necessitate to examine its indirect role in modeling agile supply chains (Koh et al., 2017). In light of the above discussion, the following hypotheses are proposed:

$H_{1 c}$ : Strategic flexibility affects the positive relationship between relationship integration (Customer) and SCA.

$H_{1 d}$ : Strategic flexibility affects the positive relationship between relationship integration (Supplier) and SCA.

\section{Employees Behavioral Flexibility and Supply Chain Agility}

Employees behavioral flexibility is capability of employees to adapt to the changes in environment (LePine, Colquitt, \& Erez, 2000). Employees behavioral flexibility ensures that the firm doesn't have to hire someone new to survive in changing environment because its employees can adapt to the changes and make overall adaptation fast. Flexibility in employees behavior is a key element to achieve agility in supply chain (Ngai, Chau, \& Chan, 2011; Gunasekaran et al., 2019). An organization must have skillful employees to implement and adapt to change. Adaptive behavior is mandatory to work in volatile environment (L. Dyer \& Shafer, 2003). Employees must have a positive attitude to change be it idea or technological change, an organization must use its ability to transform internal and external abilities to achieve dynamic capability (D. J. Teece et al., 1997). Therefore, it is proposed that:

$\mathrm{H}_{2}$ : Employees behavioral flexibility have significantly positive impact on SCA. 


\section{Moderating Role of Complexity}

Complexity driven from the theory of Contingency means the outcome of certain practice may be different in different situations. Fynes, De Búrca, and Marshall (2004) concluded that environmental context including complexity moderates relationship with supply chain partners and performance of supply chain positively, on the other hand Srinivasan, Mukherjee, and Gaur (2011) stated otherwise. In general, when complexity is high, firms are required to critically and quickly sense the failures, work closely with the suppliers, adjust the capacities and ensure the accuracy of service to become effective and responsive (Azadegan, Patel, Zangoueinezhad, \& Linderman, 2013). Therefore, it is proposed that:

$H_{3}$ : Complexity moderates the relation between relationship integration and SCA positively.

\section{Methodology}

Close ended self-administered questionnaire was used for the purpose of data collection. A total of 163 owners of Pakistani SMEs were contacted and requested to participate in the study. Out of which 147 valid responses were received with $90 \%$ response ratio. The data was collected by visiting these firms in person. The variables are specifically related to the management of the supply chain. Structural equation modelling via MPlus was used to test the model.

\section{Sample Size}

The sample size of this research study is 147 , as the sample size of similar literature varied among (100-150) so to be on the safer side the mentioned sample size has been chosen. Ding, Velicer, and Harlow (1995) after re-viewing various studies claimed that sample size of 100 - 150 respondents is the minimum requirement for satisfactory sample size when using structural equation modelling. The five to ten respondents for each variable rule is commonly used in the CFA \& SEM. Jöreskog and Sörbom (1998) suggested that the ten respondents for each variable is also appropriate. As a rule of thumb of 15 subjects per predictor is proposed by Shimizu and Hitt (2004). Thus, the sample size of 147 has been used in this research which fulfils the minimum criteria. Ten participants per variable, six in our case totalling 60; and 15 participants per independent variable, four in our case also totalling 60 .

\section{Sampling Technique}

Non-probability based sampling technique has been used, as sampling framework is not available for SMEs, hence the probability sampling cannot be pursued as suggested by (Saunders, 2011). Convenience sampling is used as it is less resource consuming and can help in meeting the required sample in limited time. It was ensured that the respondents comprised of key management functionaries working in SME sector of Pakistan. Saunders 
(2011) suggested that sample ostensibly chosen for convenience often meet purposive sampling criteria that is relevant to research aim. The organizations chosen for data collection is convenient because of easy access and in this situation the convenience sampling meets criteria of purposive sampling.

Convenience sampling is often considered effective when it comes to predicting outcomes. Correlation research is accurate with convenience sampling as the study is not of proportions of the target audience but of relation between variables (Blome, Schoenherr, \& Rexhausen, 2013).

\section{Instruments}

The questionnaire was divided into two sections. First section contained the demographic questions and second section had the items related to study variables. In order to measure supply chain agility, 14 items scale was adopted from Gligor et al. (2013); for Employees' Behavioral Flexibility, eight items scale adopted from Bhattacharya, Gibson, and Doty (2005); for strategic flexibility, 11 items scale adopted from Martínez Sánchez and Pérez Pérez (2005); for relationship integration, six items scale adapted from Stevens (1989); Narasimhan and Das (1999); for complexity, four item scale adopted from FuentesFuentes, Albacete-Sáez, and Lloréns-Montes (2004).

\section{Common Method Variance}

Common method bias (CMB) is the variation in research findings caused due to the method used in the research for data collection. Survey researches are required to be cognizant of this issue and address it into the analysis of findings (Podsakoff, MacKenzie, Lee, \& Podsakoff, 2003). There are certain procedural and statistical remedies deployed to mitigate the impact of CMB on research findings. Herman's single factor test is one of the statistical remedies to determine and control the severity of $\mathrm{CMB}$. According to them, all the items of constructs are factor analyzed and if the shared variance explained is less than $60 \%$, CMV is not considered a serious issue. In current research, all the items were factor analysed and it was determined that the explained shared variance was less than $60 \%$; which gives us confidence to claim that our research findings were not seriously affected by CMB.

\section{Results and Findings}

The study was initially pilot tested on a small sample to ensure the reliability and validity (i.e., face and content) of the used instrument. After having the acceptable results, the study was further carried out with confirmatory factor analysis and path analysis through MPlus software. Both CFA and path analysis were performed using MPlus, and the results were satisfactory as the unstandardized loadings of observed variables were more than 0.5 ; which ensured sufficient significance of observed variable as per the recommendations of Kolenikov and Bollen (2012). The below table portrays the fit indices of the tested model. 
Table 1

\begin{tabular}{|c|c|c|c|}
\hline Fit Indexes & $\begin{array}{l}\text { Criteria } \\
\text { for fit }\end{array}$ & $\begin{array}{l}\text { Model } \\
\text { value }\end{array}$ & Conclusion \\
\hline$X^{2} / \mathrm{df}$ & $<3$ & 1.433 & Satisfied \\
\hline RMSEA & $<0.08$ & 0.054 & Satisfied \\
\hline TLI & $>0.9$ & 0.927 & Satisfied \\
\hline CFI & $>0.9$ & 0.937 & Satisfied \\
\hline \multicolumn{4}{|c|}{$\begin{array}{l}\text { Note: } 1 \text {. The RMSEA value of }>0.08 \text { is unacceptable } \\
\text { and anything less is considered acceptable } \\
\text { (Hu \& Bentler, 1999). 2. CFI value of }>0.9 \text { means } \\
\text { acceptable fit (Hair, Anderson, Babin, \& Black, 2010); } \\
\text { 2. CFI value of }>0.9 \text { (Awang, 2012). 3. The TLI value } \\
\text { of }>0.9 \text { is acceptable for model fit. }\end{array}$} \\
\hline
\end{tabular}

In the above table, the convergent validity was tested through composite reliability (CR) and average variance extracted (AVE) values. According to Hair et al. (2010), if the $\mathrm{CR}$ value of the factor is 0.7 or greater and AVE is 0.5 or greater, the data will have no serious issue of convergent validity.

Table 2

Validity test

\begin{tabular}{lccccccccc}
\hline & CR & AVE & MSV & COM & EBF & RIC & RIS & SF & SCA \\
\hline COM & 0.882 & 0.715 & 0.163 & $\mathbf{0 . 8 4 6}$ & & & & & \\
EBF & 0.897 & 0.556 & 0.307 & -0.118 & $\mathbf{0 . 7 4 6}$ & & & & \\
RIC & 0.820 & 0.532 & 0.396 & 0.144 & 0.529 & $\mathbf{0 . 7 3 0}$ & & & \\
RIS & 0.863 & 0.558 & 0.396 & -0.056 & 0.554 & 0.629 & $\mathbf{0 . 7 4 7}$ & & \\
SF & 0.827 & 0.546 & 0.266 & 0.404 & 0.222 & 0.315 & 0.289 & $\mathbf{0 . 7 3 9}$ & \\
SCA & 0.836 & 0.564 & 0.289 & -0.035 & 0.538 & 0.453 & 0.424 & 0.516 & $\mathbf{0 . 7 5 1}$ \\
\hline
\end{tabular}

Discriminant validity states that the factors in study are unique and the items of one factors do not show high factor loadings with another factor. According to methodological experts (Byrne, 2013), discriminant validity is determined if the MSV (Maximum shared variance) value is lesser than AVE (MSV $<$ AVE).

\begin{tabular}{|c|c|c|c|c|c|c|}
\hline \multirow[b]{2}{*}{ Relationships } & \multicolumn{2}{|c|}{ Moderators only } & \multicolumn{2}{|c|}{ Without moderators } & \multicolumn{2}{|c|}{ Complete model } \\
\hline & Estimates & $P$ value & Estimates & $\mathbf{P}$ value & Estimates & $P$ value \\
\hline $\mathrm{RIC} \rightarrow \mathrm{SF}$ & 0.358 & 0.089 & 0.271 & 0.01 & 0.196 & 0.019 \\
\hline $\mathrm{RIS} \rightarrow \mathrm{SF}$ & 0.141 & 0.034 & 0.07 & 0.389 & 0.07 & 0.389 \\
\hline Size $\rightarrow$ SF & - & - & 0.056 & 0.019 & 0.222 & 0.01 \\
\hline $\mathrm{RIC} \rightarrow \mathrm{SCA}$ & - & - & 0.089 & 0.228 & 0.005 & 0.7 \\
\hline $\mathrm{RIS} \rightarrow \mathrm{SCA}$ & - & - & 0.007 & 0.9 & 0.272 & 0.068 \\
\hline $\mathrm{EBF} \rightarrow \mathrm{SCA}$ & - & - & 0.351 & 0 & 0.318 & 0 \\
\hline Size $\rightarrow$ SCA & - & - & -0.007 & 0.649 & -0.045 & 0.471 \\
\hline $\mathrm{SF} \rightarrow \mathrm{SCA}$ & - & - & 0.39 & 0 & 0.597 & 0 \\
\hline$(\mathrm{COMxRIC}) \rightarrow \mathrm{SCA}$ & 0.16 & 0.002 & - & - & 0.124 & 0.001 \\
\hline$($ COMxRIS $) \rightarrow$ SCA & -0.101 & 0.088 & - & - & -0.064 & 0.151 \\
\hline
\end{tabular}

The research tested for difference in populations via chi-square difference method which calculates the chi-square difference between unconstrained and constrained model and their degree of freedom and upon putting the values in the above given tool provided by Gaskin (2011), the result suggests that the relationships vary from population to population which 
is categorized by industry types in this research and the second step is to check the significance and difference at path level.

Figure 2

Structural equation model

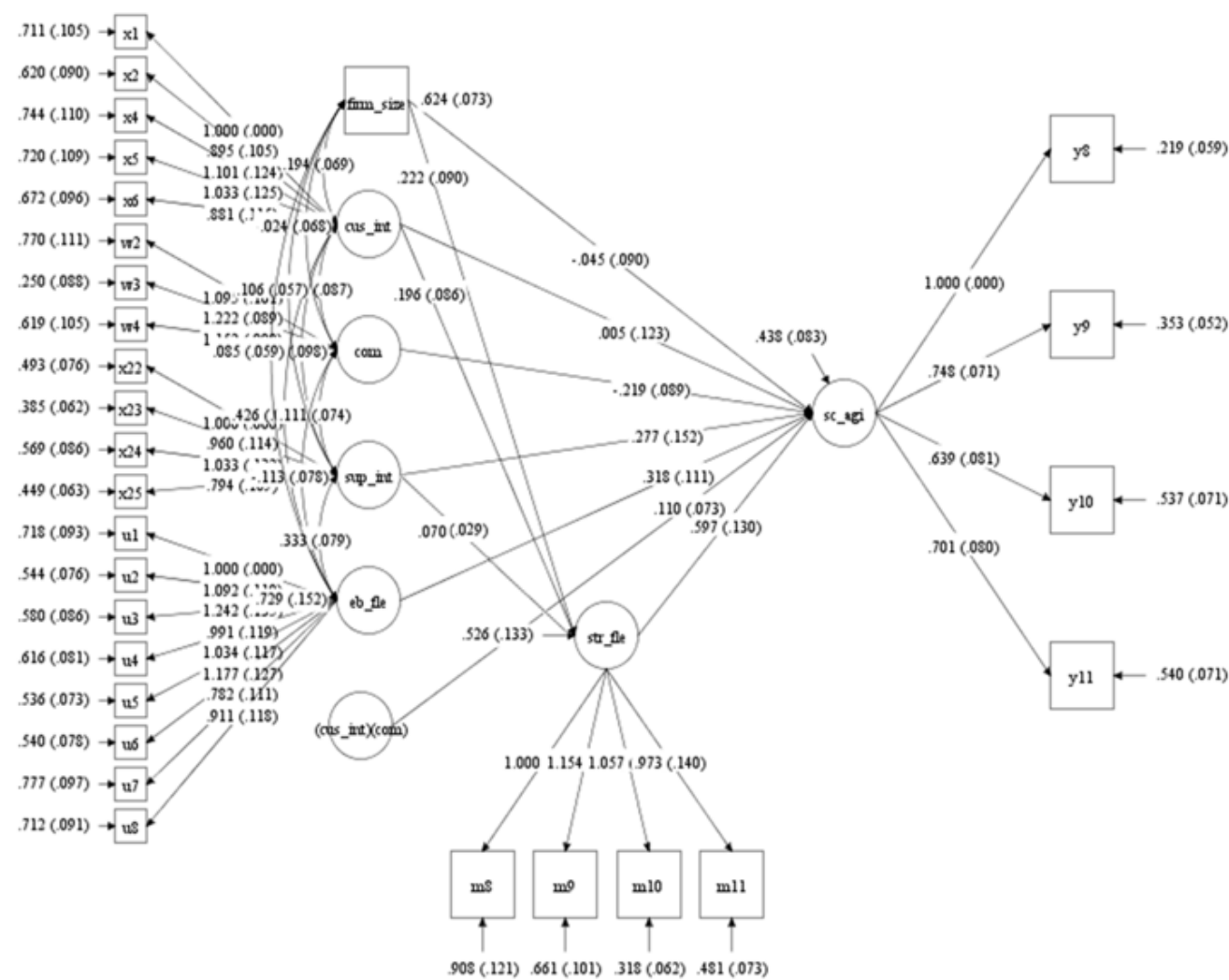

According to Figure 3, the complexity - as moderator - increase the impact of RIC on SCA. In other words, if complexity is high, it will increase the positive impact of RIC on SCA and if complexity is low, the firm may not need to involve its customers as the benefit will be negligible at best. 


\section{Figure 3}

Moderating effects

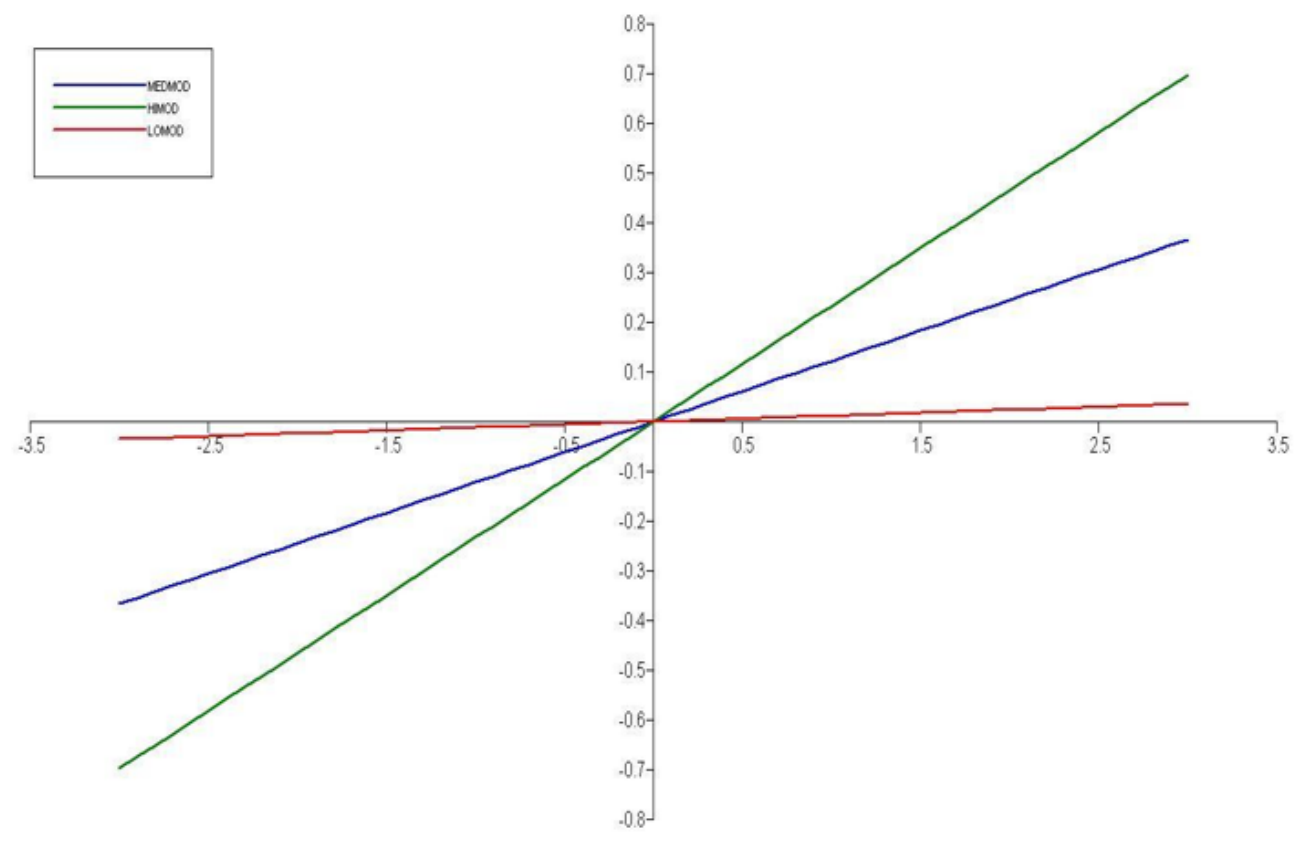

\section{Conclusion and Discussions}

The objective of this research was threefold. In the first part, it was aimed to examine the direct effect of relationship integration (i.e., customer and supplier) and employees' behavior flexibility on supply chain agility. In the second part, it was intended to examine the indirect impact of relationship integration (i.e., customer and supplier) on supply chain agility through behavioral flexibility. In the third part, it was directed to study the moderated impact between relationship integration and supply chain agility through complexity. According to the results, RIC (Customer integration) increase the strategic flexibility which further leads to higher levels of supply chain agility; though RIC has no direct impact on supply chain agility (SCA). Moreover, it was found that supplier integration (RIS) have neither direct nor indirect impact on SCA. In addition, employee behaviour flexibility (EBF) has significant direct and positive impact on SCA. On the other side, complexity did moderate the impact of RIC on SCA; however, it did not moderate the impact of RIS on SCA.

The results suggest that RIC was found to have significant indirect impact on SCA only. This, in other words, means relationship integration with customer do not directly leads to supply chain agility; however, it can only be possible with strategic flexibility. These findings are, to some extent, supporting the claims of theory of dynamic capability and relational view, which signifies that increase in RIC will result in improved strategic 
flexibility which in turn will increase supply chain agility. Additionally, these findings are also supporting the past findings on the indirect impact of customer integration on SCA (Bock, Opsahl, George, \& Gann, 2012). In addition to this, complexity did not moderate the relationship between RIS and SCA. The theoretical argument is that when complexity increases, the chance of a mishap also increases which increases the element of dynamicity. Therefore, timely exchange of information between organization and customer is crucial to adapt in time.

The results further showed that relationship integration with suppliers has no direct or indirect impact on supply chain agility. Though these findings are in contradiction with the theory of relational view and dynamic capability, however, the support of these findings are clarified by the transactional cost theory. Moreover, Marcone (2014) argued that supplier integration can be one of the reasons to decrease supply chain agility. He further explained that supplier integration increases the dependency on supplier which reduces the flexibility and, in turn, agility may go down. In addition to this, D. Teece et al. (2016) also specified that dependency on one or fewer suppliers will reduce the organizational flexibility which may affect supply chain performance. In addition to this, complexity did not moderate the relationship between RIS and SCA. Though these findings are in contradiction to the theoretical argument; support of the same can be seen in empirical literature.

Employees' behavioral flexibility was found to have significant impact on SCA. These findings are supporting dynamic capability theory which argues that internal and external capabilities play an important role in achieving dynamic capabilities. These findings are also according to the findings of past research (Rouis, 2010) conducted in other settings.

\section{Contributions of Current Study}

The findings of current research suggest that the relationship between relational integration and agility is due to strategic flexibility. These findings are in contrast to some past studies where downstream supply chain was considered more important than downstream supply chain. The findings of this study claims that close ties with customers and distributors helps in developing and maintaining agile and flexible supply chains. These findings broaden the understanding on some of the past researches (Fayezi \& Zomorrodi, 2015) which proposed a conceptual model to comprehend agile supply chain portfolio. In addition, these findings are also validating the arguments of Avittathur and Swamidass (2007) who emphasize the importance of partner relationships in creating flexible and adaptable supply chains. They further added that those firms create more profitable supply chains which share similar views on flexibility and reflect best match of adaptability in their processes. Overall, the findings of current research are in lines with Avittathur and Swamidass (2007) who added a new dimension by advancing relationship-centric view in developing and maintaining flexibility in supply chains.

In the context of SMEs, it has been identified that internal factors play a more important role than external factors because SMEs usually deal with highly customized products and their customer database is relatively small. Overall, the results of the current study suggest that SMEs are required to develop close ties with their customers and invest in activities to make supply chain more flexible and agile. As per the findings, it is advisable to Pakistani 
SMEs to allocate resources to activities that build flexible supply chains and enhance the relationship with customers. Moreover, it is desirable to invest in activities that create strong ties among downstream supply chain partners. These findings are also useful for Multinational firms for their strategic planning in developing and maintaining flexible and agile supply chains with local Pakistani SMEs.

Moreover, it is also recommended to develop policies and offer programs to enhance employees' behavioral flexibility as it has been found as an important element to achieve agility. EBF can be improved by training employees or hiring the ones which show little resistance to change.

\section{Limitations and Future Research}

This research is not without limitations. First, this research was carried out in crosssectional manner, future research may be conducted in longitudinal settings to test the findings from another angle. Second, this research has only considered complexity as a moderator. Other research may consider other factors as a moderator to extend the theoretical and empirical understanding of proposed research framework. Third, this study was carried out in Pakistani SMEs sector; therefore, these findings may not be transferable to other regions. Therefore, there is a need to further validate the findings in other cultural settings. In order to best meet the requirements of research objectives with the accessible data, this research adopted a survey based approach. Future researches are suggested to look for more objective data, if accessible. It is also suggested for future researches to replicate the current framework in large scale firms to test the external validity of the findings and generalizability of the proposed model. 


\section{References}

Aaker, D. A., \& Mascarenhas, B. (1984). The need for strategic flexibility. Journal of Business Strategy, 5(2), 74-82.

Agarwal, A., Shankar, R., \& Mandal, P. (2006). Effectiveness of information systems in supply chain performance: A system dynamics study. International Journal of Information Systems and Change Management, 1(3), 241-261.

Aitken, J., Christopher, M., \& Towill, D. (2002). Understanding, implementing and exploiting agility and leanness. International Journal of Logistics, 5(1), 59-74.

Allred, C. R., Fawcett, S. E., Wallin, C., \& Magnan, G. M. (2011). A dynamic collaboration capability as a source of competitive advantage. Decision Sciences, 42(1), 129-161.

Argyris, C. (1982). Reasoning, learning, and action: Individual and organizational. JosseyBass.

Aslam, H., \& Azhar, T. M. (2018). Dynamic capabilities and performance: A supply chain perspective. Pakistan Journal of Commerce and Social Sciences (PJCSS), 12(1), 198-213.

Avittathur, B., \& Swamidass, P. (2007). Matching plant flexibility and supplier flexibility: Lessons from small suppliers of US manufacturing plants in India. Journal of Operations Management, 25(3), 717-735.

Awang, Z. (2012). Structural equation modeling using amos graphic. Penerbit Universiti Teknologi MARA.

Azadegan, A., Patel, P. C., Zangoueinezhad, A., \& Linderman, K. (2013). The effect of environmental complexity and environmental dynamism on lean practices. Journal of Operations Management, 31(4), 193-212.

Bhattacharya, M., Gibson, D. E., \& Doty, D. H. (2005). The effects of flexibility in employee skills, employee behaviors, and human resource practices on firm performance. Journal of Management, 31 (4), 622-640.

Blome, C., Schoenherr, T., \& Rexhausen, D. (2013). Antecedents and enablers of supply chain agility and its effect on performance: A dynamic capabilities perspective. International Journal of Production Research, 51(4), 1295-1318.

Bock, A. J., Opsahl, T., George, G., \& Gann, D. M. (2012). The effects of culture and structure on strategic flexibility during business model innovation. Journal of Management Studies, 49(2), 279-305.

Boehm, B. (2002). Get ready for agile methods, with care. Computer(1), 64-69.

Bowman, E. H., \& Hurry, D. (1993). Strategy through the option lens: An integrated view of resource investments and the incremental-choice process. Academy of Management Review, 18(4), 760-782.

Braunscheidel, M. J., \& Suresh, N. C. (2009). The organizational antecedents of a firm's supply chain agility for risk mitigation and response. Journal of Operations Management, 27(2), 119-140.

Byrne, B. M. (2013). Structural equation modeling with Mplus: Basic concepts, applications, and programming. Routledge.

Chiang, C.-Y., Kocabasoglu-Hillmer, C., \& Suresh, N. (2012). An empirical investigation of the impact of strategic sourcing and flexibility on firm's supply chain agility. 
International Journal of Operations $\&$ Production Management, 32(1), 49-78.

Childerhouse, P., Aitken, J., \& Towill, D. R. (2002). Analysis and design of focused demand chains. Journal of Operations Management, 20(6), 675-689.

Christophe, M., \& Gaudenzi, B. (2015). Managing risks in sustainable supply chains. Sinergie, 96 .

Christopher, M., \& Gattorna, J. (2005). Supply chain cost management and value-based pricing. Industrial marketing management, 34 (2), 115-121.

Clements, M. D., Dean, D. L., \& Cohen, D. A. (2007). Proposing an operational classification scheme for embryonic cooperative relationships. Journal of Management \&5 Organization, 13(1), 51-64.

Dierickx, I., \& Cool, K. (1989). Asset stock accumulation and the sustainability of competitive advantage: Reply. Management Science, 35(12), 1514-1514.

Ding, L., Velicer, W. F., \& Harlow, L. L. (1995). Effects of estimation methods, number of indicators per factor, and improper solutions on structural equation modeling fit indices. Structural Equation Modeling: A Multidisciplinary Journal, 2(2), 119-143.

Dyer, J. H., \& Singh, H. (1998). The relational view: Cooperative strategy and sources of interorganizational competitive advantage. Academy of Management Review, 23(4), 660-679.

Dyer, L., \& Shafer, R. A. (2003). Dynamic organizations: Achieving marketplace and organizational agility with people. CAHRS Working Paper Series, 27.

Fayezi, S., \& Zomorrodi, M. (2015). The role of relationship integration in supply chain agility and flexibility development: an australian perspective. Journal of Manufacturing Technology Management, 26(8), 1126-1157.

Fuentes-Fuentes, M. M., Albacete-Sáez, C. A., \& Lloréns-Montes, F. J. (2004). The impact of environmental characteristics on TQM principles and organizational performance. Omega, 32(6), 425-442.

Fynes, B., De Búrca, S., \& Marshall, D. (2004). Environmental uncertainty, supply chain relationship quality and performance. Journal of Purchasing and Supply Management, 10(4-5), 179-190.

Gaskin, J. (2011). Multigroup moderation in amos made easy. Retrieved from http:// youtube.com/Gaskination

Gligor, D. M., Holcomb, M. C., \& Stank, T. P. (2013). A multidisciplinary approach to supply chain agility: Conceptualization and scale development. Journal of Business Logistics, 34(2), 94-108.

Goldman, S. L., Nagel, R. N., \& Preiss, K. (1995). Agile competitors and virtual organizations: strategies for enriching the customer. Van Nostrand Reinhold New York.

Gunasekaran, A., Yusuf, Y. Y., Adeleye, E. O., Papadopoulos, T., Kovvuri, D., \& Geyi, D. G. (2019). Agile manufacturing: an evolutionary review of practices. International Journal of Production Research, 57(15-16), 5154-5174.

Hair, J., Anderson, R., Babin, B., \& Black, W. (2010). Multivariate data analysis: A global perspective. NJ: Pearson Upper Saddle River.

Hameed, I., Waris, I., \& ul Haq, M. A. (2019). Predicting eco-conscious consumer behavior using theory of planned behavior in Pakistan. Environmental Science and Pollution Research, 26(15), 15535-15547. 
Harland, C. M. (1996). Supply chain management: Relationships, chains and networks. British Journal of Management, 7, 63-80.

Hu, L.-t., \& Bentler, P. M. (1999). Cutoff criteria for fit indexes in covariance structure analysis: Conventional criteria versus new alternatives. Structural Equation Modeling: A Multidisciplinary Journal, 6(1), 1-55.

Irfan, M., Wang, M., \& Akhtar, N. (2019). Enabling supply chain agility through process integration and supply flexibility. Asia Pacific Journal of Marketing and Logistics.

Jöreskog, K., \& Sörbom, D. (1998). LISREL 8.20 and PRELIS 2.20 [computer program]. Chicago: Scientific Software Inc.

Kantola, J. I., Nazir, S., \& Barath, T. (2018). Advances in human factors, business management and society: Proceedings of the AHFE 2018 international conference on human factors, business management and society.

Khan, S. A., Liang, Y., \& Shahzad, S. (2014). Adoption of electronic supply chain management and e-commerce by small and medium enterprises and their performance: A survey of SMEs in Pakistan. American Journal of Industrial and Business Management, 4(09), 433.

Koh, S. L., Gunasekaran, A., Morris, J., Obayi, R., \& Ebrahimi, S. M. (2017). Conceptualizing a circular framework of supply chain resource sustainability. International Journal of Operations \& Production Management, 37(10), 1520-1540.

Kolenikov, S., \& Bollen, K. A. (2012). Testing negative error variances: Is a heywood case a symptom of misspecification? Sociological Methods 85 Research, 41(1), 124-167.

LePine, J. A., Colquitt, J. A., \& Erez, A. (2000). Adaptability to changing task contexts: Effects of general cognitive ability, conscientiousness, and openness to experience. Personnel Psychology, 53(3), 563-593.

Malekifar, S., Taghizadeh, S. K., Rahman, S. A., \& Khan, S. U. R. (2014). Organizational culture, it competence, and supply chain agility in small and medium-size enterprises. Global Business and Organizational Excellence, 33(6), 69-75.

Marcone, M. R. (2014). Purchasing strategies portfolio: A multifaceted approach in medium multinationals. Piccola Impresa/Small Business(3).

Martínez Sánchez, A., \& Pérez Pérez, M. (2005). Supply chain flexibility and firm performance: A conceptual model and empirical study in the automotive industry. International Journal of Operations \& Production Management, 25(7), 681-700.

Maylor, H., Meredith, J. R., Söderlund, J., \& Browning, T. (2018). Old theories, new contexts: extending operations management theories to projects. International Journal of Operations 85 Production Management, 38(6), 1274-1288.

Mitrega, M., Forkmann, S., Zaefarian, G., \& Henneberg, S. C. (2017). Networking capability in supplier relationships and its impact on product innovation and firm performance. International Journal of Operations \& Production Management, 37(5), $577-606$.

Nagel, R. N., \& Dove, R. (1991). 21st century manufacturing enterprise strategy: An industry-led view. Diane Publishing.

Narasimhan, R., \& Das, A. (1999). An empirical investigation of the contribution of strategic sourcing to manufacturing flexibilities and performance. Decision Sciences, $30(3), 683-718$. 
Ngai, E. W., Chau, D. C., \& Chan, T. (2011). Information technology, operational, and management competencies for supply chain agility: Findings from case studies. The Journal of Strategic Information Systems, 20(3), 232-249.

Palmier, C. (2014). An investigation into leagile, lean and agile manufacturing at local manufacturing firms (Unpublished master's thesis). University of Malta.

Parente, R. C., Baack, D. W., \& Hahn, E. D. (2011). The effect of supply chain integration, modular production, and cultural distance on new product development: A dynamic capabilities approach. Journal of International Management, 17(4), 278-290.

Podsakoff, P. M., MacKenzie, S. B., Lee, J.-Y., \& Podsakoff, N. P. (2003). Common method biases in behavioral research: A critical review of the literature and recommended remedies. Journal of Applied Psychology, 88(5), 879-903.

Price, D., Beach, R., Muhlemann, A. P., Sharp, J. A., \& Paterson, A. (1998). A system to support the enhancement of strategic flexibility in manufacturing enterprises. European Journal of Operational Research, 109(2), 362-376.

Rasouli, M. R. (2019). Intelligent process-aware information systems to support agility in disaster relief operations: A survey of emerging approaches. International Journal of Production Research, 57(6), 1857-1872.

Ritchie, B., \& Brindley, C. (2004). Risk characteristics of the supply chain-a contingency framework. Supply Chain Risk, 28-42.

Rouis, S. (2010). Impact of supply chain agility on long term relationship in service industry. In Paper presented at the association information and management conference.

Saunders, M. N. (2011). Research methods for business students. India: Pearson Education.

Savrul, M., Incekara, A., \& Sener, S. (2014). The potential of e-commerce for SMEs in a globalizing business environment. Procedia-Social and Behavioral Sciences, 150, $35-45$.

Senge, P. (1990). Peter senge and the learning organization. Academy of Management Review, 3(3), 413-427.

Shimizu, K., \& Hitt, M. A. (2004). Strategic flexibility: Organizational preparedness to reverse ineffective strategic decisions. Academy of Management Perspectives, 18(4), $44-59$.

Simatupang, T. M., \& Sridharan, R. (2005). The collaboration index: A measure for supply chain collaboration. International Journal of Physical Distribution 85 Logistics Management, 35(1), 44-62.

Srinivasan, M., Mukherjee, D., \& Gaur, A. S. (2011). Buyer-supplier partnership quality and supply chain performance: Moderating role of risks, and environmental uncertainty. European Management Journal, 29(4), 260-271.

Ståhle, M., Ahola, T., \& Martinsuo, M. (2019). Cross-functional integration for managing customer information flows in a project-based firm. International Journal of Project Management, 37(1), 145-160.

Stank, T. P., Keller, S. B., \& Daugherty, P. J. (2001). Supply chain collaboration and logistical service performance. Journal of Business Logistics, 22(1), 29-48.

Stevens, G. C. (1989). Integrating the supply chain. International Journal of Physical Distribution \& Materials Management, 19(8), 3-8. 
Swafford, P. M., Ghosh, S., \& Murthy, N. (2008). Achieving supply chain agility through it integration and flexibility. International Journal of Production Economics, 116(2), 288-297.

Teece, D., Peteraf, M., \& Leih, S. (2016). Dynamic capabilities and organizational agility: Risk, uncertainty, and strategy in the innovation economy. California Management Review, 58(4), 13-35.

Teece, D. J., Pisano, G., \& Shuen, A. (1997). Dynamic capabilities and strategic management. Strategic Management Journal, 18(7), 509-533.

Wernerfelt, B. (1984). A resource-based view of the firm. Strategic Management Journal, $5(2), 171-180$. 